Ann. Génét. Sél. anim., 1975, 7 (3), 317-319.

NOTE

\title{
DEUX CAS DE FUSION CENTRIQUE CHEZ BOS TAURUS L. EN SUISSE
}

\author{
C. P. POPESCU, E. P. CRIBIU et P. TSCHUDI* \\ avec la collaboration technique de Jeannine BosCHER \\ Union Nationale des Coopératives d'Élevage et Insémination artificielle, \\ et Laboratoire de Génétique factorielle C. N.R.Z., \\ 78350 Jouy en Josas (France) \\ * Klinik für Nutztiere und Pferde der Universität Bern, \\ Längasstrasse, 124, CH-3012 Bern (Suisse)
}

\section{RÉSUMÉ}

Une fusion centrique de type $1 / 29$ a été observée chez deux taureaux Simmental demi-frères issus d'un taureau qui avait une mauvaise fertilité.

Plusieurs descendants d'un taureau Simmental appartenant à la Fédération Suisse d'insémination artificielle, étaient soupçonnés, après un examen cytogénétique sommaire, porteurs d'une translocation robertsonienne. Le caryotype du père qui avait une mauvaise fertilité, abattu en I97I, n'a pas été étudié. Par contre, nous avons pu étudier le caryotype de deux de ses fils, nés en 1974 .

Des cultures de sang intégral ont été réalisées selon la méthode de De Grouchy et al, (1964). Toutes les cellules étudiées, chez les deux animaux, portaient le chromosome fusionné de type I/29 (fig. I). Le père était, sans doute, au moins hétérozygote pour cette anomalie.

Dans la race Simmental, la translocation $\mathrm{r} / 29$ a déjà été décrite par deux fois. Herzog et Höнx (I97I) en Allemagne la trouvent, à l'état hétérozygote chez une femelle atteinte du syndrome d'Arnold-Chiari. En Angleterre, HARvey (1972, $a$ et $b$ ) identifie la même anomalie chez deux animaux sur 26 étudiés au total. L.e premier, une femelle retournée en oestrus 13 fois, était homozygote pour cette anomalie $\left(58, \mathrm{XY}, t^{+} t^{+}\right)$et le second, un mâle, hétérozygote $\left(59, \mathrm{XY}, t^{+}\right)$.

Les translocations chromosomiques autosomales n'ont généralement pas d'expression phénotypique visible. Par conséquence, la translocation $\mathrm{r} / 29$ trouvé par Herzog et $\mathrm{HöHN}$, peut être considérée indépendante du syndrome d'ARNold-ChIARI, dont l'animal porteur était atteint. 


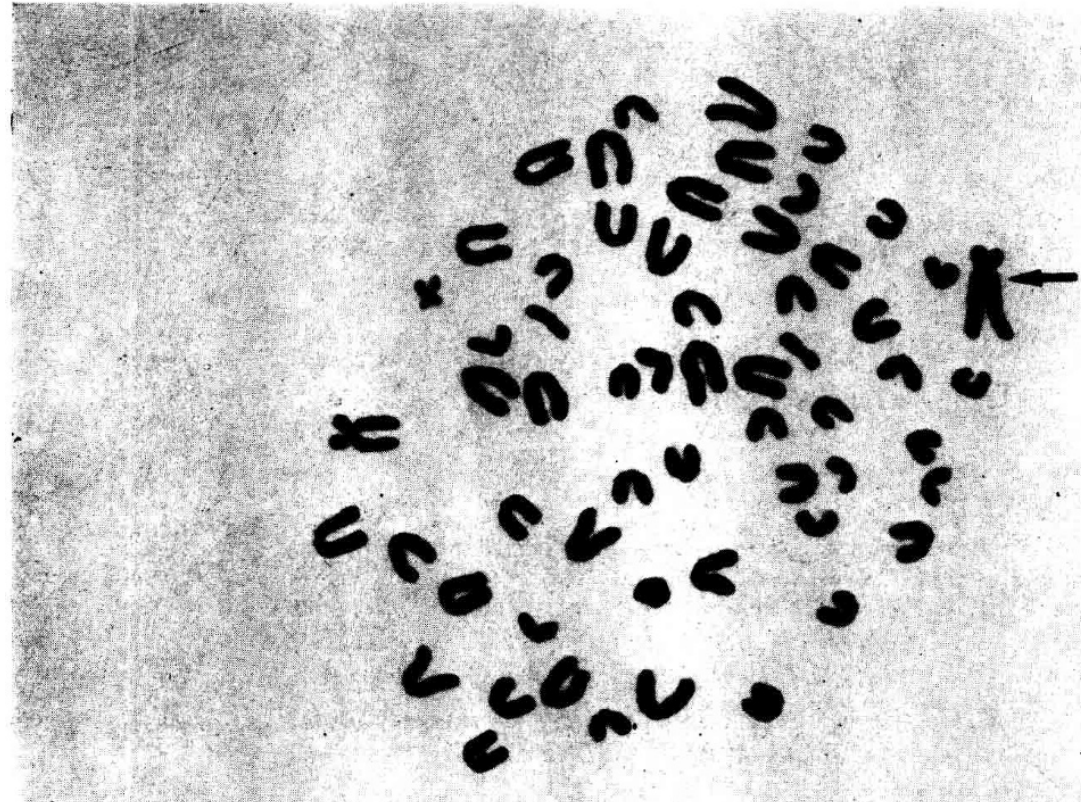

a

a no no no na

no no in an nn

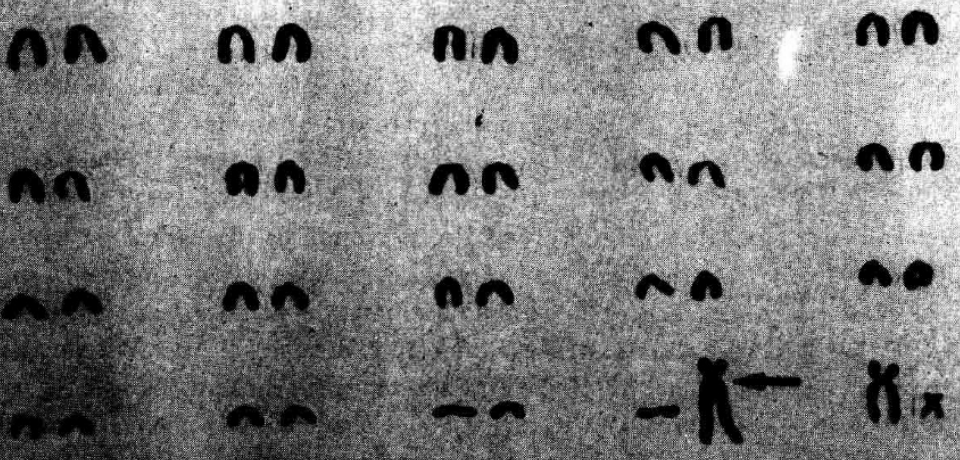

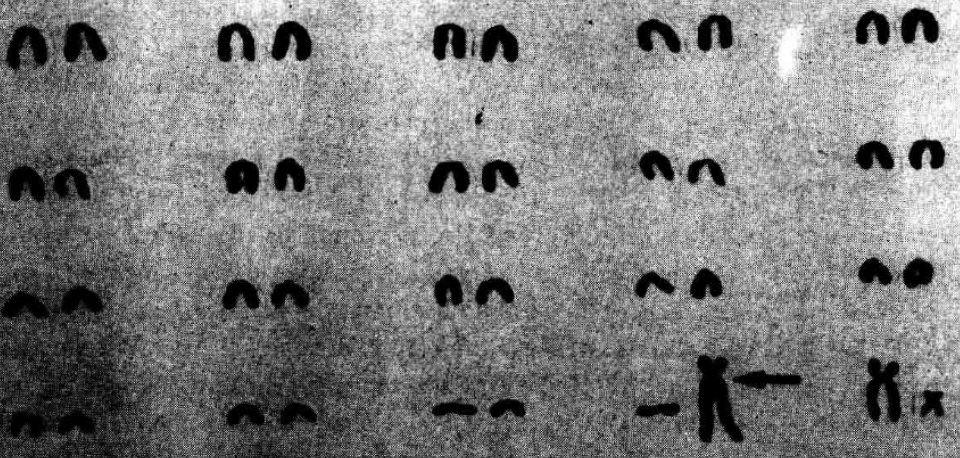

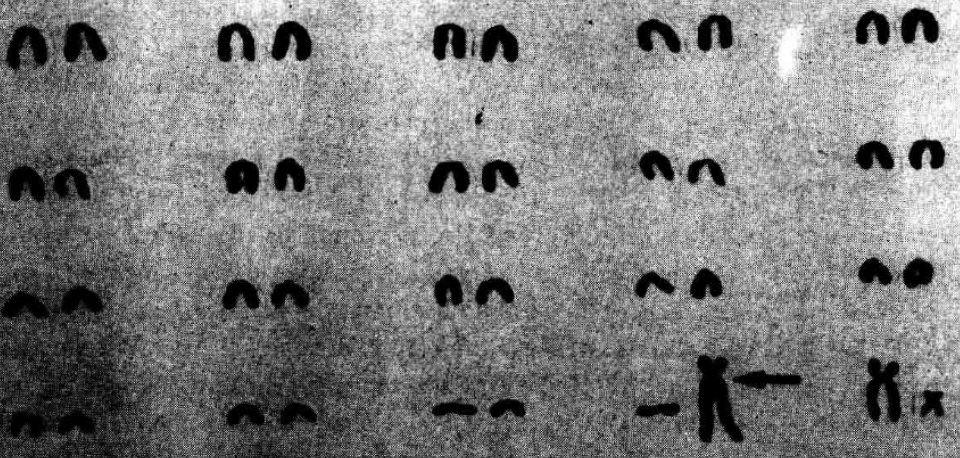

FIG. I. - Métaphase (a) et caryotype (b) portant la fusion centrique 1/29 Le chromosome anormal est marqué par une flèche 
Rappelons qu'en Simmental, BruÈre et Chapman (1973) ont trouvé en Nouvelle-Zélande chez un animal originaire d'Écosse, une autre translocation robertsonienne qui, elle, implique un. chromosome de la $1 I^{e}$ ou $12^{e}$ paire et un autre, appartenant à la $15^{e}$ ou $16^{e}$ paire autosomale Il s'est avéré plus tard que cet animal était le fils d'un taureau écossais porteur, lui aussi, de l'anomalie (HARVEY, 1974).

\section{REMERCIEMENTS}

Les prélèvements de sang ont été fournis par le Dr J. Reuse, Sempach (I.U) Suisse.

\section{SUMMARY}

\section{TWO NEW CASES OF CENTRIC FUSION IN SWISS CATTLE}

Two new cases of centric fusion are described in Simmental breed of Switzerland.

\section{RÉFÉRENCES BIBLIOGRAPHIQUES}

BrUíre A. N., Chapman H. M., 1973. Autosomal translocations in two exotic breeds of cattle in New-Zealand. Vet. Rec., 82, 615-620.

De Grouchy J., Roubin M., Passage E., r964. Microtechnique pour l'étude des chromosomes humains, à partir d'une culture de leucocytes sanguins. Ann. Génét., 7, 45.

HaRvey H. J. A., r972 a. Chromosome analysis of cattle in Great-Britain. VII. Internat. Congr. Anim. Reprod. Artif. Insem. Munich, Iror-r ro3.

HaRvey H. J. A., I972 b. Chromosome abnormalities of cattle in Britain. Vet. Rec., 91, 630.

Harver H. J. A., I974. Chromosome analysis of cattle populations. Vet. Rec., 94, 227.

Herzog A., HöhN H., I971. Zytogenetische Befunden bei angeborenen Anomalien des Zentralnervensystems des Rindes. Ann. Génét. Sell. Anim., 3, 225-234. 